\begin{tabular}{c|c|c}
\hline \hline & CLIMATE RESEARCH \\
Vol. 26: 233-249, 2004 & Clim Res & Published June 18 \\
\hline \hline
\end{tabular}

\title{
Southwest Australia past and future rainfall trends
}

\author{
B. Timbal* \\ Bureau of Meteorology Research Centre, GPO Box 1289k, Melbourne, Victoria 3001, Australia
}

\begin{abstract}
A statistical method, based on the idea of analogous synoptic situations, is used to study the observed rainfall trends in the SW of Western Australia. The method has been developed and optimised by relating patterns of atmospheric fields (predictors) to station records of rainfall (predictands), for both rain occurrences and daily rain amounts. When tested on observational data, the analogue method is able to reproduce the trend observed globally during the past 50 yr, showing the sensitivity of the statistical approach to changed climatic conditions. The choice of predictor has an important impact on the results: mean sea level pressure (MSLP) and vertically integrated precipitable water (PWTR) are both important in explaining the observed local rainfall trend. The model is then applied to 3 coupled models' simulations of the current climate. The improvement gained when using the statistical downscaling tool over direct model grid-average outputs is substantial. Most of the model biases are removed and realistic probability distribution functions at the station level are obtained. The method is then applied to altered climate conditions; the impact of model sensitivities on large-scale responses is quantified using the various coupled models. Future trends for rainfall, estimated by direct climate model outputs, are compared with downscaled projections. A general agreement is found; uncertainties are smaller amongst projections when the downscaling technique is used. All projections agree on a mean reduction of total rainfall in winter and spring. The possible impact of future drying trends induced by global warming is compounded by changes in mean and extreme rainfall, such as long wet spells and large yearly totals.
\end{abstract}

KEY WORDS: Statistical downscaling $\cdot$ Climate change $\cdot$ Rainfall $\cdot$ Australia

\section{INTRODUCTION}

Rainfall in the SW tip of the Australian continent is unusual in many aspects. It differs from other locations at similar latitudes on the western edges of land masses (Gentilli 1972). The Australian continent is affected by the warm Leeuwin Current, flowing from the tropics, while the western edge of continental masses in Africa or South America are affected by cold currents flowing toward the equator. The annual mean Sea Surface Temperature (SST) is around $20^{\circ} \mathrm{C}$ off Perth, compared to 15 or $16^{\circ} \mathrm{C}$ at the same latitude along the coasts of South America and Africa. The warm waters increase the efficiency of the advection of atmospheric moisture onto the Australian region (Wright 1974a). The average rainfall for the tip of the continent below a line from $30^{\circ} \mathrm{S}, 115^{\circ} \mathrm{E}$ to $35^{\circ} \mathrm{S}$, $125^{\circ} \mathrm{E}$ is $600 \mathrm{~mm}$, with a local maximum $>1000 \mathrm{~mm}$ on the western escarpment. Similar latitudes on the other continents receive less than $300 \mathrm{~mm}$. Rainfall in the SW corner of Australia (SWA) is highly seasonal with up to $80 \%$ of the rain recorded during the 6 month period from May to October (Wright 1974a,b).

Since the mid-1970s, SWA has experienced a dramatic decrease in annual rainfall of 10 to $20 \%$ (IOCI 1999). This reduction is observed in the early part of the wet season from May to July, while it does not affect the spring rainfall from August to October (IOCI 2001). Natural variability and human induced climate change have been suggested as the most plausible causes of this observed trend (IOCI 1999, 2001). Although it is possible to fit a linear trend to the observation, the trend can also be explained using breaks in the mean rainfall following Hubert (1997). Although rainfall gauges exhibit significant break points, there is no spatial consistency amongst the stations regarding 
the occurrence of these breaks; they occurred between 1932 and 1974 (Nicholls et al. 1999). Therefore, in this study linear trends are considered on both the 1958-1978 and 1958-1998 periods, as well as the difference between the mean rainfall prior to and after 1978. This rainfall trend has often been linked to largescale changes in atmospheric conditions that took place in the mid-1970s (Allan \& Haylock 1993).

The Mediterranean climate of this region, on the edge of a large continental dry land surrounded by large ocean masses, is difficult to simulate with largescale models due to the sharp contrast between climatic zones. Current atmospheric General Circulation Models (GCMs) have a spatial resolution of a few hundred kilometres and thus represent the SW of Western Australia only with a handful of grid points (typically 6 or 9 points). Furthermore, due to heavy numerical smoothing, GCMs are not realistic on spatial scales smaller than several grid cells (McAvaney et al. 2001), and are unlikely to provide an accurate representation of localised rainfall maxima. Therefore, GCMs may not be the most appropriate tool to study the trend in SWA and its possible mechanisms. Such models, forced with observed SSTs for the past century, do not reproduce the observed drying trend and, on the contrary, suggest an increase in total rainfall (Smith et al. 2001). One possible explanation, raised by the authors, is that 'Rainfall is not sufficiently well simulated by large scale climate models to capture trends at the relatively small scale' (summary, p. vii).

A statistical method linking large-scale atmospheric variables to local rainfall is an alternative to numerical modelling, where the impact of large-scale atmospheric changes in the past 40 years can be 'downscaled' to local rainfall. Such an approach can help determine which large-scale changes can empirically explain the locally observed drying trend in SWA. Following the validation step, the downscaling technique can be applied to climate change simulations produced by GCMs and can be used to predict future rainfall trends for this part of the Australian continent.

A very simple conceptual way to link large-scale synoptic situations to local weather is to use the analogue approach first described by Lorenz (1969), to complement Numerical Weather Prediction (NWP). The analogue technique has resurfaced in the past decade for climate applications, and has been applied for mid-latitude climates (Zorita et al. 1995, Martin et al. 1997, Timbal \& McAvaney 2001, Timbal et al. 2003). Simple and easy to implement, the analogue technique compares well with more sophisticated methods (Zorita \& von Storch 1999).

The low computational cost of statistical downscaling makes it possible to use several coupled GCMs, in order to test the sensitivity of the downscaled projections to large-scale modelled changes. Such an estimate of the uncertainties due to climate model sensitivity is critical information for impact studies. The need for more uncertainty analysis in policy decision and in integrated assessment models has increased the recognition of downscaling techniques in constructing climate change scenarios for impact studies (McCarthy et al. 2001) to the point that Katz (2002) argues 'there is value in adding a downscaling layer to the analysis, even if no "downscaling" literally needs to take place' (p. 180).

Two levels of uncertainty are investigated in this study: (1) Uncertainties due to the imperfect knowledge and representation of physical processes in the atmosphere. Atmospheric model sensitivities are complicated by coupling processes giving a broad range of response to radiative forcings (Meehl et al. 2000). This gives rise to differences in the simulation of large-scale climate response to identical anthropogenic forcing. Three state-of-the-art coupled GCMs from different origins and with a wide range of sensitivity (Cubasch et al. 2001) are used in this study. (2) The role of the various large-scale predictors. Charles et al. (1999) have shown the complementary role of the moisture field to dynamical predictors for downscaling rainfall. Therefore, it is critical to implement within the technique a part of expert judgement and to understand dynamical large-scale changes and their impact on the local scale (Risbey et al. 2002). In this study, the nonstationarity of the climate in SWA is used to test the predictors.

After a description of the datasets (surface observations, analyses used to train the statistical model and GCM outputs), the Statistical Model (SM) is developed for rainfall occurrences and amount. Its skill and ability to reproduce the observed drying trend is then assessed, as well as the role of various large-scale forcings, to explain the trend. Then, the SM is applied to GCM simulation and is shown to correct the defaults of modelled rainfall in SWA. Finally, future trends are compiled by applying the technique to transient simulations from the coupled models. The downscaled future projections are intercompared and put in perspective with those provided directly by the GCMs. A special emphasis is put on extreme rainfall events.

\section{DATASETS}

To build and thoroughly validate a Statistical Model (SM), a long set of data is mandatory for both predictors and predictands. In the case of the analogue approach, the length of the record is critical for finding a suitable analogue (Van den Dool 1994). The predictants are daily rainfall observations at 32 sites (Fig. 1). Many more rain gauges have been or are currently 
used in this region, but only sites providing high quality daily observations (Lavery et al. 1992) over the past $40 \mathrm{yr}$ were used. These criteria reduce the number of possible observations, but are mandatory since the predictands' data quality has a strong impact on the analogue model (Timbal et al. 2003). Most of the stations are located inland, west of $120^{\circ} \mathrm{E}$; further east, the low density of observations corresponds to sparsely populated areas. The reliability of the data is high and very few missing days are reported; $50 \%$ of the stations have less than $1 \%$ of missing data over the 1958-2000 period.
The drying trend observed in the region can be

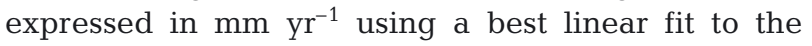
observations for 1958-1998 for both early winter, May-July (referred to as winter hereafter), and spring, August-October (Fig. 2). A large area of strong rainfall decrease is observed in the central and southern part of the region in winter, with small patches of increased rainfall along the Southern Ocean coast and inland further east and north. Most of this drying trend occurred in the 1960s and 1970s, with no significant trend in the 1980 s and 1990s. In spring, the regional average shows a very small increase in total rainfall $(<10 \mathrm{~mm}$ over

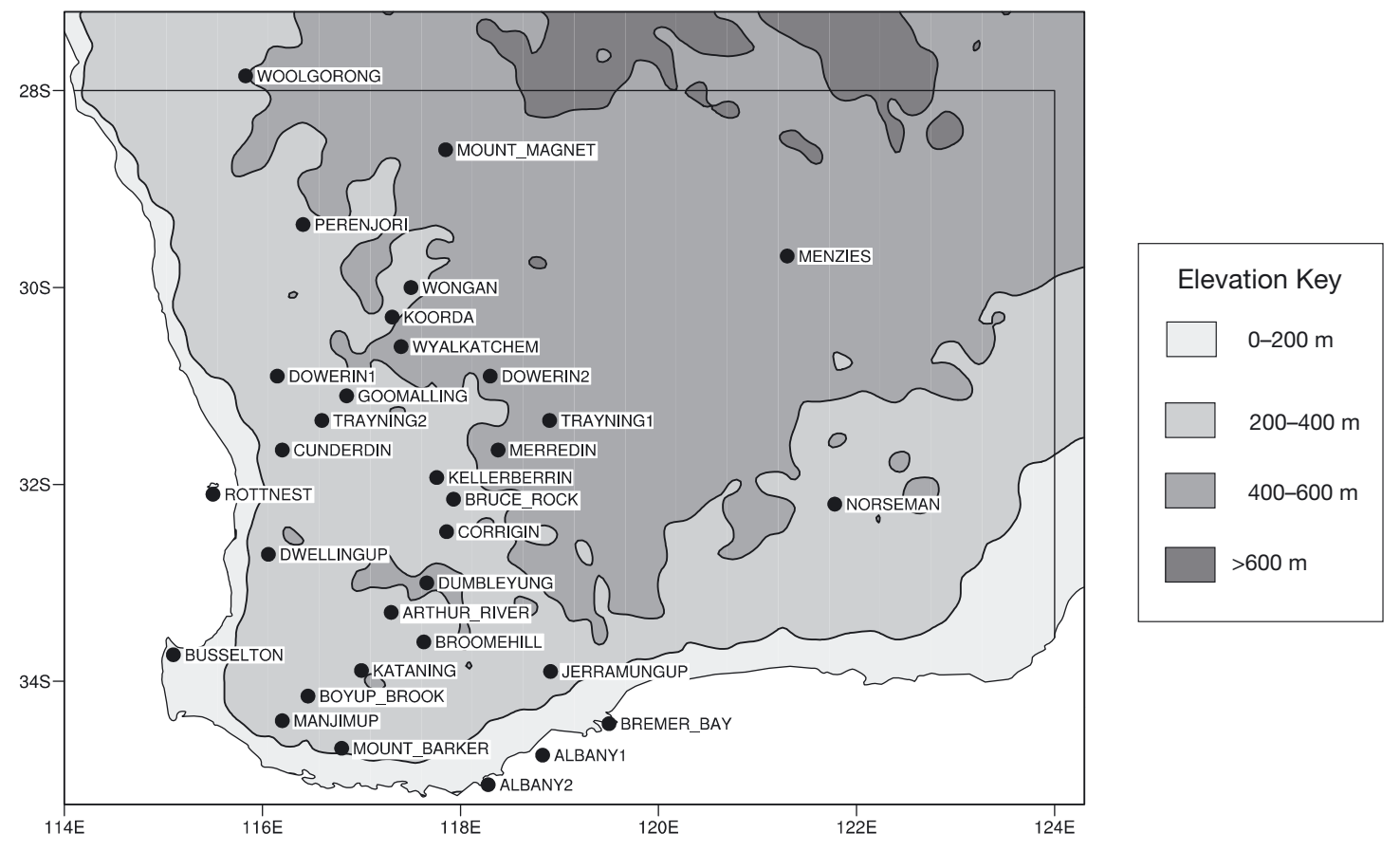

Fig. 1. High quality rainfall stations in the SW of Australia
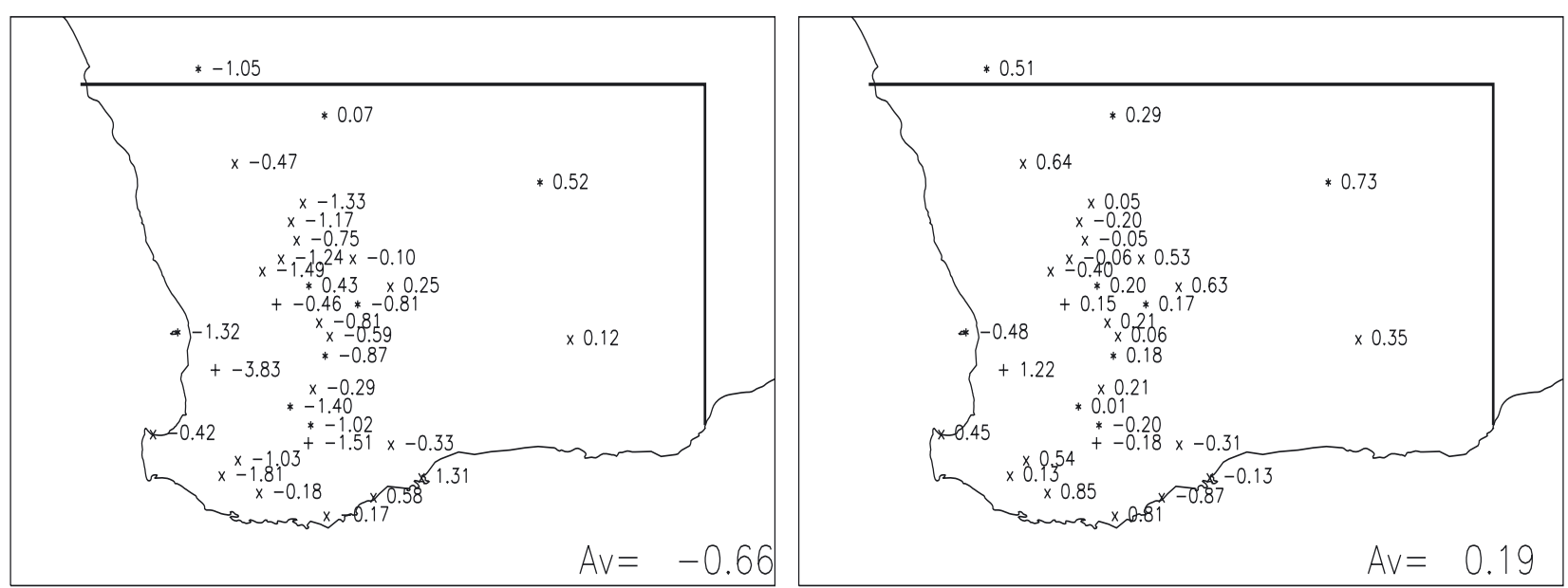

Fig. 2. Observed linear rainfall trends $\left(\mathrm{mm} \mathrm{yr}^{-1}\right)$ for 1958-1998 in winter (left) and spring (right). Each station symbol corresponds to a data quality: ${ }^{*}$ is the highest quality and + the lowest (based on percentage of missing data in the record) 
$40 \mathrm{yr}$ ), but there is no large-scale coherent signal. Increases are confined to the far east and north of the region, while in the central part, several nearby stations show opposing trends.

Large-scale 'observed' predictors are derived from the National Centers for Environmental Prediction (NCEP) and the National Center for Atmospheric Research (NCAR) collaborative re-analyses (hereafter: NNR). This is a record of global analyses of atmospheric fields, on a $2.5 \times 2.5^{\circ}$ grid, from 1958 to the present (Kalnay et al. 1996). NNR are produced using a frozen global data assimilation system. Most of the variables used in this study are strongly influenced by observed data, and hence are the most reliable, except for Precipitable Water (PWTR), a variable which is strongly influenced by the model. The use of the NNR prior to 1958 (Kistler et al. 2001) was investigated. Some preliminary tests showed that the skill of the model drops when the $50 \mathrm{yr}$ of NNR are used compare to the $40 \mathrm{yr}$ period analysed here. The positive effect of increasing the size of the pool of analogues was less that the negative effect due to finding unsuitable analogue based on the poorly analysed situation prior to 1958. This difference is significant at the $99 \%$ level. Following these results, I decided to use the NNR only on the most trustworthy period from 1958-1998. This time interval corresponds to the most reliable rainfall observations and importantly to the period where most of the observed drying trend took place.

Three coupled global atmospheric and oceanic models (CAOGCMs) were used. The models were all integrated at similar low horizontal resolution of the order of $500 \mathrm{~km}$ and were interpolated for consistency on the NNR grid. For the sake of brevity, only a short description of the model features is provided here. The global performances and climate change projections of the models have been assessed in the Coupled Model Intercomparison Project (CMIP: Meehl et al. 2000, Lambert \& Boer 2001) and in the third IPCC scientific assessment (Houghton et al. 2001). The models are labelled according to their respective modelling centres: Bureau of Meteorology Research Centre (BMRC; McAvaney et al. 1993, Power et al. 1993), Commonwealth Scientific and Industrial Research Organization (CSIRO; Gordon \& O'Farrel 1997), and Laboratoire de Météorologie Dynamique (LMD; Braconnot et al. 1997). The models have major differences in the numerical scheme used to solve the dynamical equations and the physical parameterisation packages. The CSIRO and BMRC models are flux corrected to limit control model drift away from observed climatology, but the LMD model is not. Daily fields were extracted for $20 \mathrm{yr}$ of the simulation, at the time when $\mathrm{CO}_{2}$ concentrations reach double the present values following the IPCC 92a transient scenario (Kattenberg et al.
1996). The LMD scenario was different: $20 \mathrm{yr}$ were extracted after the coupled model remained at a constant double $\mathrm{CO}_{2}$ value for roughly $50 \mathrm{yr}$. Moreover, 20 yr were extracted from each coupled model control run, from corresponding model years, in order to eliminate similar model biases in both experiments. This is a common practice to retain the climate change signal, although nonlinearity in the development of model drifts might not be accounted for (Raper \& Cubasch 1996).

\section{VALIDATION OF THE DOWNSCALING TECHNIQUE}

Rainfall is a critical variable for climate impact studies, but difficult to simulate accurately due to its nonnormal distribution with a large number of days with zero rainfall, and a few days with very large rainfall. Two aspects of rainfall have to be looked at: daily rain occurrences and rainfall amounts. Following the success of the application of the technique to daily extremes of temperature (Timbal \& McAvaney 2002), the application of the technique to rainfall was tested (Timbal et al. 2003). The technique appeared successful for rain occurrence, but yielded poor results for rainfall amount, in particular for the summer. However, in this study, only winter and spring rainfall are considered. Most rainfall events in these seasons are large-scale and are more successfully reproduced by any synoptic downscaling approach than are convective (small-scale) rainfall events (Wilby et al. 1998). Rainfall is a more stochastic variable than temperature, with smaller spatial and temporal correlation; a synoptic approach relying on large-scale forcing might have some limitations. Most previous attempts to downscale rainfall have used some form of stochastic conditional behaviour based on weather regimes (cf. Wilby et al. 1998 for an inter-comparison, and Charles et al. 1999 for an application to SWA). Nevertheless, the simplicity of the technique is an advantage which will be used to investigate large-scale forcings on local rainfall. The first step is to identify large-scale atmospheric predictors that drive local rainfall. The choice of predictors has to be limited to the most credible fields from climate models, e.g. no attempt was made to use derived fields which compound model fields and therefore add errors. Several predictors were tested: synoptic atmospheric fields, such as mean sea level pressure (MSLP), geopotential height at low $(1000 \mathrm{hPa})$ and mid (500 hPa) levels; low level air flows ( $\mathrm{U}, \mathrm{V}$ components, and vorticity, VOR, and divergence, DIV, of the flow); thermal variables such as $T_{850}$ and the geopotential difference $Z_{1000}-Z_{500}$; and variables indicative of the moisture content in the atmosphere 
(Precipitable Water, PWTR, and Outgoing Longwave Radiation, OLR). The predictors were used on a small domain around SWA: from 101 to $136^{\circ} \mathrm{E}$ longitude and 43 to $23^{\circ} \mathrm{S}$ latitude. To quantify the skill of the analogue model, indices were developed for rain occurrence and rain amount. The reproduction of rain occurrence was assessed using the index $I$ (Timbal \& McAvaney 2003):

$$
I=100 \times\left(1-\frac{m}{w+m}-\frac{f}{d+f}\right)
$$

where $w$ is a wet day $\left(>0.1 \mathrm{~mm} \mathrm{~d}^{-1}\right)$ forecast and observed; $d$ is a dry day $\left(<0.1 \mathrm{~mm} \mathrm{~d}^{-1}\right)$ forecast and observed; $m$ is a wet day missed by the forecast; and $f$ is a dry day falsely forecast as wet.

This index gives $100 \%$ for a perfect forecast $(m=f=$ $0)$. It would give a value of 0 for a random choice of uncorrelated days $(w=m$ and $f=d$ ). This index also takes into account the asymmetrical partition between dry and wet days. A simple scheme of extreme persistence, which would assume either rain (or no rain) every day would have a score of 0 , unless such extreme persistence is true to the observation, giving a perfect score of $100 \%$.

For rain amount, the Brier Skill Score (BSS) was used (Wilks 1995):

$$
\mathrm{BSS}=100 \times\left(\frac{\mathrm{RMSE}_{\mathrm{ref}}-\mathrm{RMSE}_{\mathrm{anal}}}{\mathrm{RMSE}_{\mathrm{ref}}}\right)
$$

where RMSE is the Root Mean Square Error between the observed and reconstructed series; ref is the reference model, a random choice of analogue; and anal is the analogue model.

Although these indices are not directly comparable, higher scores are obtained for rain occurrences then for rain amount (Fig. 3) for most single predictors. The best results for most predictors are achieved in winter for occurrences, and in spring for amount. Synoptic fields are usually the most predictive of rain occurrences, although PWTR in winter, and low level divergence also show high skill. For rain amount, low level vorticity in spring and divergence in winter are the best predictors.

Results in summer (not shown) are lower, confirming that winter and spring rainfall are more driven by large-scale forcing and can likely be reproduced by a synoptic based downscaling technique such as the analogue. The 6 month period from May to October represents $80 \%$ of the annual rainfall in SWA (Wright 1974a) and therefore the analogue technique appears appropriate to study SWA rainfall in both spring and winter.

Other parameters of the Statistical Model (SM) were optimised differently than for temperature (Timbal et al. 2003). The best matrix to define the analogues was
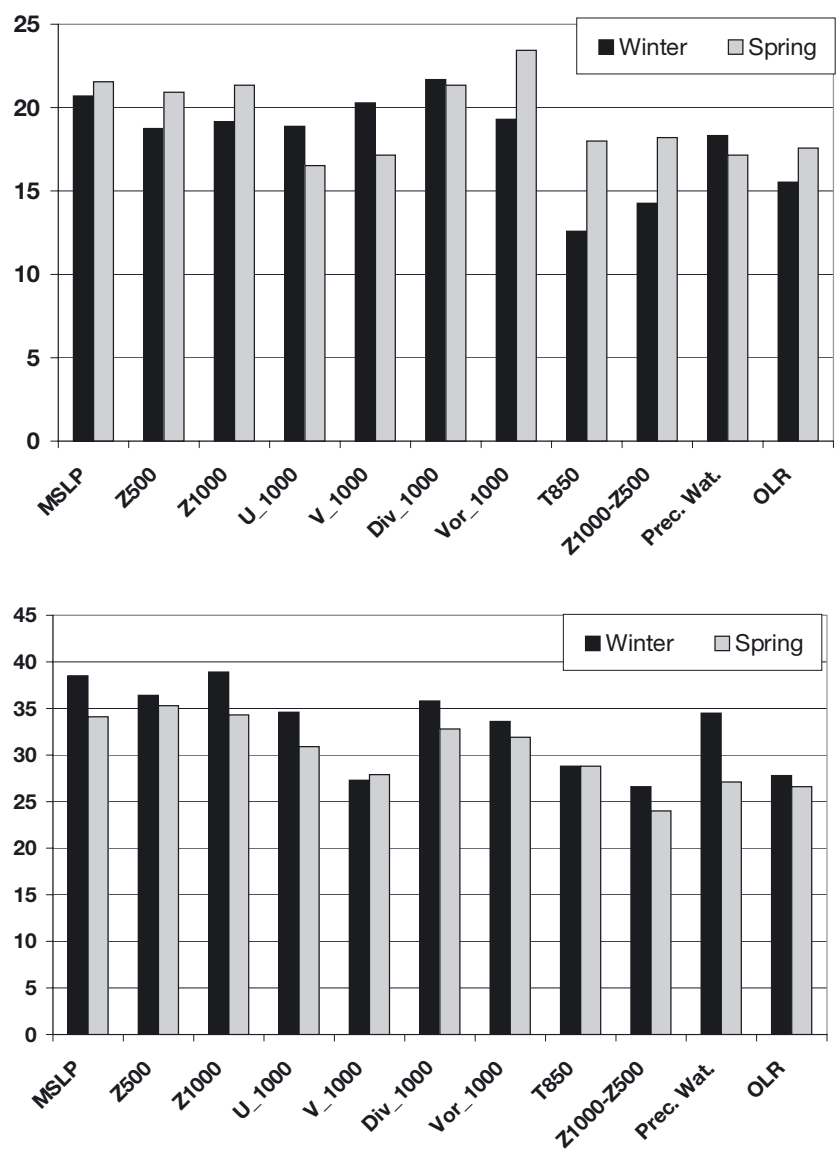

Fig. 3. Skill of the analogue model using a single predictor for rainfall amount (top) and occurrences (bottom). Skill-scores are explained in the text

found to be calculated on transient atmospheric states (Barnett \& Preisendorfer 1978) over a $24 \mathrm{~h}$ period from 00:00 $\mathrm{h}$ UTC. This allows us to match the period on which the rainfall measurement is accumulated from 09:00 h local time: 00:00 h UTC in SWA. Other parameters include the use of the seasonal or monthly mean to calculate the departure of the predictors from the mean climate and the option to restrict the choice of analogue within the same $30 \mathrm{~d}$ calendar period, or over the entire season. These parameters, of lesser importance, were used to test the sensitivity of the results to the choice of analogue and to obtain confidence interval for the results.

Several combinations of predictors were found to increase the skill of individual predictors. Finally, an optimal model was formed for all stations and both seasons, combining PWTR with a dynamical field MSLP and the low level (1000 hPa) divergence of the flow $\left(D_{1000}\right)$. This optimal combination was tested using various skill scores (Table 1). The BSS based on RMSE (RMS-S), a similar score based on correlation (Corr-S) and the index $I$ for occurrence (Occ-S) were used. The 
Table 1. Comparison of the skill of the analogue method with persistence and NCAR collaborative re-analyses (NNR) direct model outputs (DMO) in winter and spring, averaged over all stations. See text for definition of the skillscore

\begin{tabular}{|lccc|}
\hline & Analogue & Persistence & NNR DMO \\
\hline Winter & & & \\
Corr-S & 36 & 13 & 24 \\
RMS-S & 26.7 & 7.6 & 25.3 \\
Occ-S & 38.5 & 30.7 & 32.9 \\
Summer & & & \\
Corr-S & 24 & 13 & 17 \\
RMS-S & 26.7 & 9.5 & 25.4 \\
Occ-S & 32.9 & 27.0 & 28.0 \\
\hline
\end{tabular}

Table 2. Comparison between the analogue technique and NCAR collaborative re-analyses (NNR) direct model outputs (DMO) of the reproduction of the observed rainfall series, averaged over the entire domain. Results with the analogue downscaling technique are shown for the crossvalidated model using analogues for 1978-1998 and 1958-1977

\begin{tabular}{|lccc|}
\hline & NNR DMO & \multicolumn{2}{c|}{ Analogue } \\
& & $1978-1998$ & $1958-1977$ \\
\hline Winter & & & \\
Rain days (\%) & 86.8 & 96.1 & 95.7 \\
Total rainfall (mm) & 56.3 & 82.5 & 85.1 \\
Variance (\%) & 61.1 & 68.5 & 80.0 \\
Spring & & & \\
Rain days (\%) & 79.8 & 91.0 & 91.3 \\
Total rainfall (mm) & 53.3 & 73.9 & 83.1 \\
Variance (\%) & 30.3 & 58.4 & 73.7 \\
& & & \\
\hline
\end{tabular}

SM beat persistence in all cases. More importantly, the model was tested against NNR Direct Model Outputs (DMO) for rainfall. To do so, the nearest grid point is compared to the local observation. Rainfall in the reanalyses is not constrained by data assimilation and therefore is a modelled variable calculated with 'perfect' atmospheric conditions. The analogue supersedes NNR modelled rainfall for all statistics and for both seasons. Although this result was anticipated, since DMO are representative of a grid average rather than a point value (Skelly \& Henderson-Sellers 1996), it is a mandatory step to ensure that a downscaling approach adds value (Palutikof et al. 1997). The difference for rainfall amount is small based on RMS-S, but large based on Corr-S. This suggests that the parameterisation used to model rainfall has been tuned to produce smaller RMS errors.

Once the optimisation step was completed using the 1978-1998 period, the statistical model was applied to the 1958-1977 period. This is an interesting test due to the drying trend: the mean rainfall is lower during the development period than in the test period. One of the major issues regarding statistical downscaling is the applicability of the statistical relationship to changed climate conditions. The ability of the technique to reproduce the non-stationarity of the climate in SWA observed in the past $50 \mathrm{yr}$ is critical. Analogues for any day in the wetter 1958-1977 period are selected from the dryer 1978-1998 period. This ensures a full crossvalidation of the model's skill.

Global statistics of the reconstructed series are compared with the observed ones for both the analogue technique and the NNR modelled rainfall (first 2 columns in Table 2). In all cases, the analogue method improves the reproduction of the observed rainfall characteristics compared to direct modelled rainfall. Of particular interest is the reproduction of the variance, which was reduced when the technique was applied to temperature (Timbal \& McAvaney 2002). Similar results are seen for rainfall, with only $68.5 \%$ in winter and $58.4 \%$ in spring of the observed variance reproduced. The reconstructed series show another bias: a 5 to $10 \%$ underestimation of rain occurrences. Both biases lead to a reduction of the total rainfall amounts. These biases could be due to an intrinsic fault of the statistical model, which does not reproduce the observed variance; alternatively, this tendency could be due to the choice of analogous situations from a dryer climatic state.

In order to test these 2 hypotheses, the analogue model was tested, non-crossvalidated, with analogues chosen from the same period: 1958-1977. The only constraint was then to choose an analogue from a different calendar year. These analogue reconstructed series exhibit a similar dryer climate (last column in Table 2) for rain occurrences. This suggests that the fitting period bears no influence on bias toward dry climate regarding rain occurrences. All other statistics are closer to observation than in the crossvalidated case. The reproduction of variance is strongly improved. Picking analogues for heavy rainfall days in the crossvalidated case is difficult and leads to a poor reconstruction of the observed variance. The impact on total rainfall is a better reproduction of the observed totals. It is important to keep in mind this limitation identified during the validation when analysing the results further.

\section{REPRODUCTION OF THE OBSERVED TREND}

The ability of the SM to reproduce the observed drying trend was tested. Averaged over all stations, the linear trend fitted to the winter series reconstructed with the SM agrees well with the observed trend (Fig. 4). At the station level, $50 \%$ of the sites have an observed trend within the uncertainties attached to the 

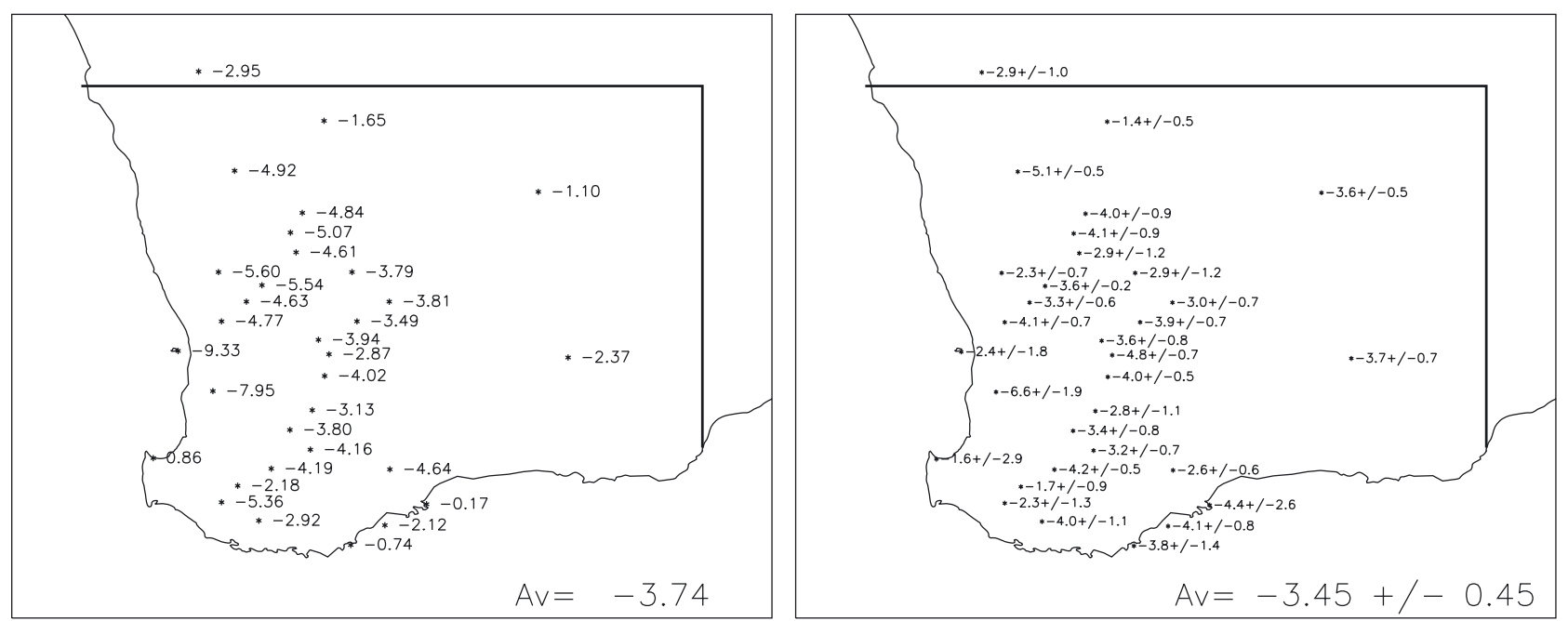

Fig. 4. Linear trend fitted on winter rainfall $\left(\mathrm{mm} \mathrm{yr}^{-1}\right)$. Left-hand panel: observed data for 1958-1977. Right-hand panel: trend reproduced with the analogue model using 1978-1998 observations. Results are averaged over 4 statistical models with uncertainties attached

reconstructed series. The uncertainties are calculated using 4 different analogue models with slightly different parameters to perturb the choice of the best analogue. The interval provides an estimate of the sensitivity of the results to the choice of the best analogue, the mean is the average of the 4 models. Differences between nearby reconstructed series are smaller than observed, which suggests that despite a large part of the trend being explained by large-scale predictors, part of the local signal is due to conditions not captured using the large-scale forcing. These discrepancies are not entirely surprising since linear trends calculated on 20 yr series are bound to have a large degree of uncertainty. Areas where the reproduced trends are consistently overestimated by the SM are coastal stations on the edge of the Southern Ocean and remote inland stations in the east. The opposite is true for coastal sites facing westerly air flow along the Indian Ocean coast. In spring, the analogue reconstructed series reproduces the small trend toward a wetter season. From 1958-1977, rainfall increased by $1.8 \mathrm{~mm} \mathrm{yr}^{-1}$ on average, the analogue reconstructed series has an increase of $1.5 \mathrm{~mm} \mathrm{yr}^{-1}$; the geographical patterns (not shown) are not significantly different.

To reduce the importance of sampling issues on the linear trend, the same calculations were made on the 40 yr period for both the observations (see Fig. 2) and the analogue model (Fig. 5). Analogues days were chosen in the same time interval, but in a different calendar year. Since most of the reduction in rainfall occurred in the earlier decades, trends are smaller. The reconstructed series gave broadly similar results on the longer period, with the notable exception of the coastal stations along the Southern Ocean, which exhibit small upward trends as observed on the 1958-1998 period. At the station level similar discrepancies are seen over this longer period. The reconstructed series are more spatially coherent than the observations, underscoring the importance of local features. Despite the uncertainties associated with fitting a linear trend on a short time interval, results obtained on the $20 \mathrm{yr}$ drying trend are confirmed on a longer period, adding confidence to these findings.

Overall, the combination of MSLP, PWTR and $D_{1000}$ is successful in reproducing the average trend observed in SW Australia rainfall. A further step is to infer the role of each predictor in reproducing this trend. The analogue model was re-run over the $40 \mathrm{yr}$ with one predictor omitted. Both MSLP and PWTR (Fig. 5) were found to have a strong impact; while the removal of $D_{1000}$ (not shown) did not. Therefore, in the rest of this study, $D_{1000}$ will be omitted from the analogue model. In the absence of PWTR as a predictor, the reconstructed series exhibit a smaller overall drying trend with a tendency toward increased rainfall in most of the southerly sites. This result is coherent with the findings of Charles et al. (1999) that atmospheric moisture is important to downscale rainfall in SWA and that largescale changes of MSLP and atmospheric moisture are driving local rainfall changes (IOCI 2001). When MSLP is omitted, the analogue model overestimates the overall trend. This overestimation is very strong for southerly stations. Therefore, the overall observed trend appears to be due to a combination of MSLP and PWTR forcing, both changes being critical in the southern part of the domain, but with an opposite effect. Less difference is seen in the central part, where both MSLP and PWTR seem to capture the trend. 

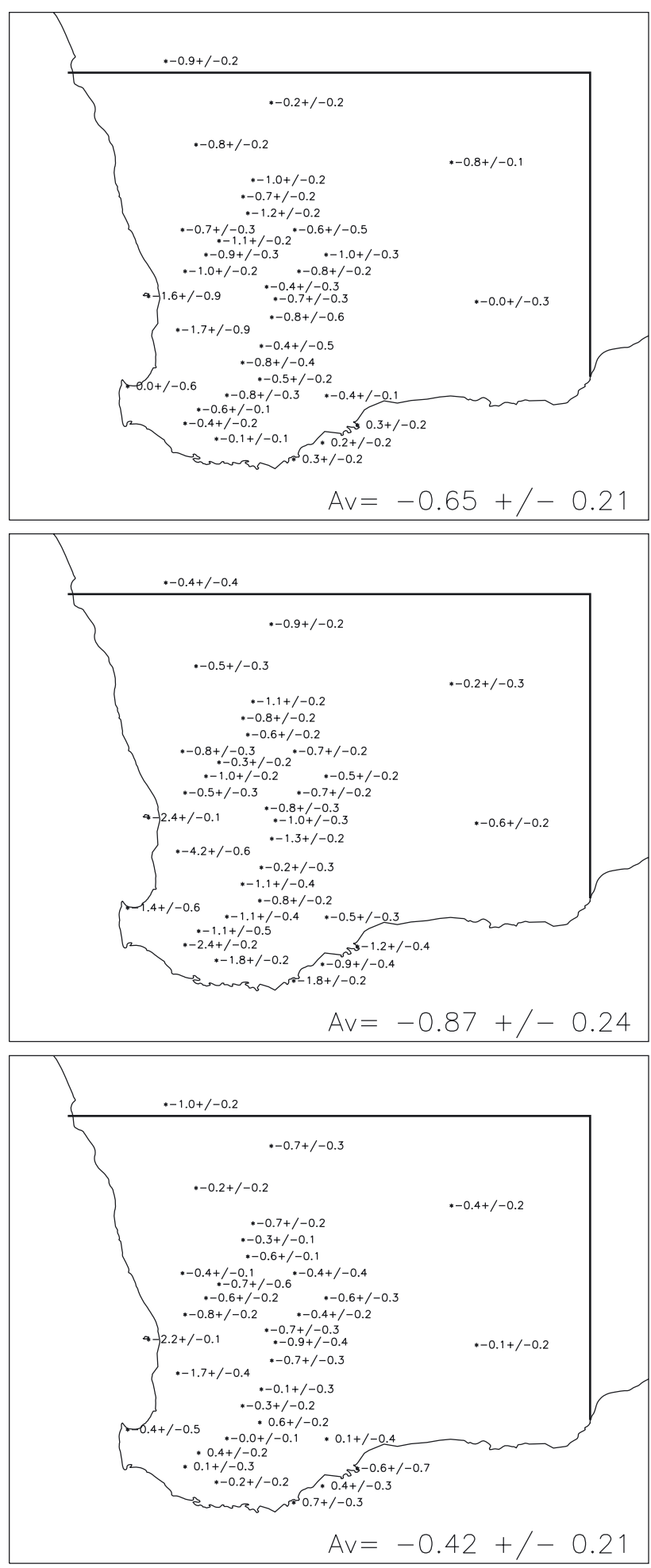

Fig. 5. Linear trend fitted on winter rainfall $\left(\mathrm{mm} \mathrm{yr}^{-1}\right)$ reconstructed series. Top panel: using the full analogue model; middle panel: without mean sea level pressure (MSLP) as a predictor; bottom panel: without precipitable water (PWTR) as a predictor. Results are averaged over 4 statistical models with uncertainties attached
Reproducing the observed drying trend in SWA has been a challenge for global climate models (Smith et al. 2001). Therefore, it is interesting to analyse further why these trends are well reproduced with the analogue approach. A linear trend was fitted to the largescale forcings that explain the local rainfall trend: MSLP and PWTR. The MSLP field, as analysed in the NNR, exhibits an increase of the high pressure belt situated across the Southern Indian Ocean and the southern part of the Australian continent in winter (Fig. 6). The storm track also is more active, but its extension northward, and hence the passage of frontal systems over SWA, is reduced. The main difference to the spring pattern (Fig. 6) is that the separation between the positive and negative anomalies is situated further north over Western Australia. The increase of the gradient between the anticyclonic belt and the storm track is similar, but without a reduction of the penetration of frontal systems over the continent. PWTR trends are similar in winter and spring (Fig. 6, bottom panels), with a marked land-sea contrast. PWTR generally increases over the oceans with a large band of decrease covering the Australian continent. The linear decrease in PWTR over $40 \mathrm{yr}$ is about $0.4 \mathrm{~mm}$, or $3 \%$ of the total precipitable water in spring, but larger in winter: $1.2 \mathrm{~mm}$, or $7 \%$ of the mean value. These largescale trends point toward a combined effect of reduced atmospheric moisture available over the continent with less penetration of frontal systems to explain the winter rainfall trend in SWA. In spring, the small reduction of atmospheric moisture does not lead to a reduction of rainfall, due to the strong penetration of frontal disturbances over the continent.

Following the identification of large-scale trends which relate to the local rainfall trends, the reasons why global models have been unable to reproduce the winter rainfall reduction is investigated using a 2 step approach. The first step is to fit a linear trend to the NNR modelled rainfall (Fig. 7). Despite the 'perfect' knowledge of the large-scale atmospheric evolution, the model is unable to reproduce the observed local rainfall trend. Either the model resolution (about $500 \mathrm{~km}$ grid square) or the physical scheme used to parameterise rainfall, is not able to handle the particular behaviour observed in this small region. In contrast, the downscaling technique, which by-passes the physical parameterisations and resolves the scaling issue, has the ability to interpret the large-scale atmospheric forcing to reproduce the local observed trend.

The second step is to analyse a global model integrated using SST observed during the second half of the 20th century. The same BMRC model (McAvaney \& Colman 1993) was used to perform a Climate of the 20th Century (C20C) experiment, using observed SSTs for the past century as a unique forcing of an atmos- 
pheric model (Frederiksen \& Zheng 2004). Model results for 1958-1998 were downscaled using the same SMs applied to the NNR. The overall trend is an increase of rainfall in winter (Fig. 7), opposite to what was observed and even larger than with the NNR direct rainfall. The geographical pattern is also a mirror image of the real world: with larger increases in rainfall in the SW and smaller increases further inland.
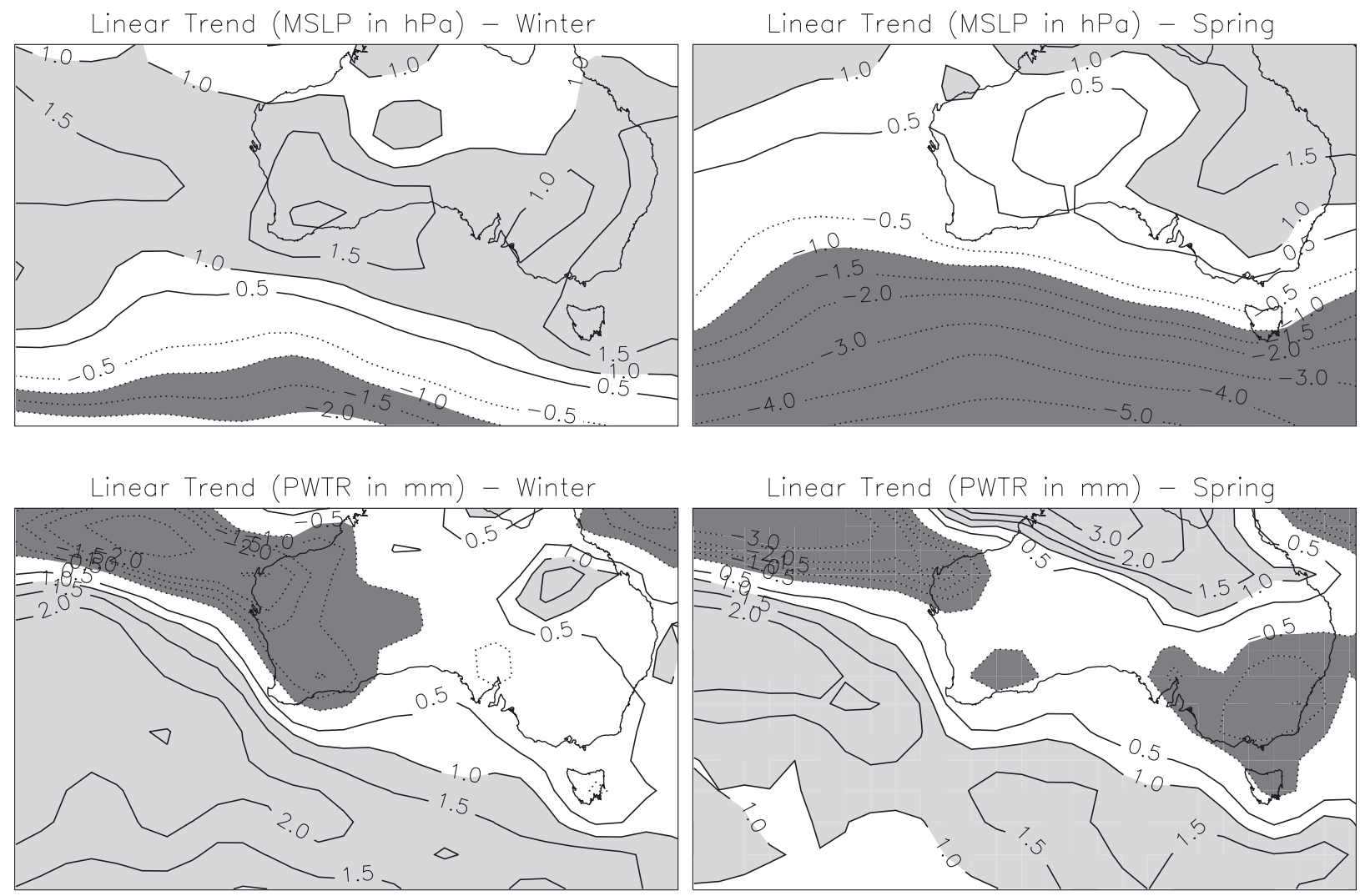

Fig. 6. Linear trend fitted on the NNR for 1958-1998, for mean sea level pressure (MSLP) (top panels) and precipitable water (PWTR)(bottom panels) in winter (left-hand panels) and spring (right-hand panels)
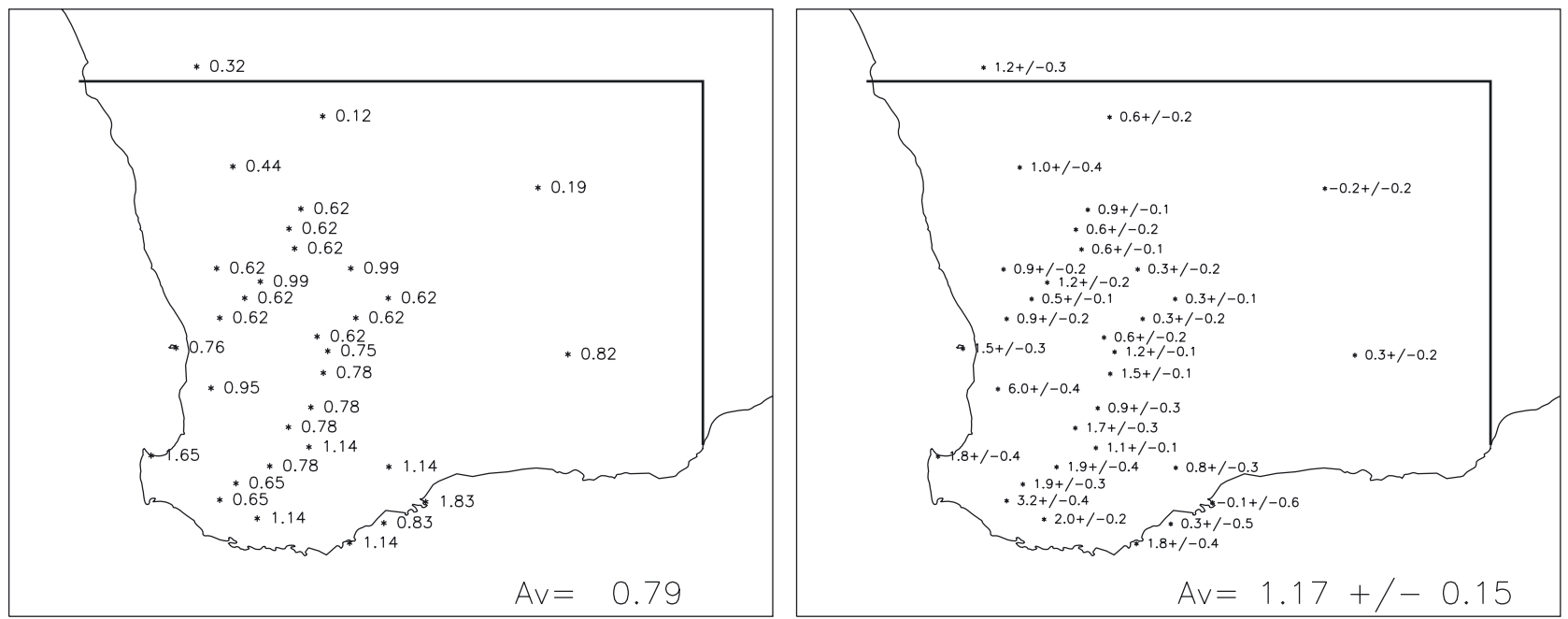

Fig. 7. Linear trend for 1958-1998 fitted to NNR winter rainfall ( $\mathrm{mm} \mathrm{yr}^{-1}$ ) (left-hand panel), and obtained using the analogue downscaling approach applied to a simulation of the climate of the 20th century (right-hand panel). Results are averaged over 4 statistical models with uncertainties attached 


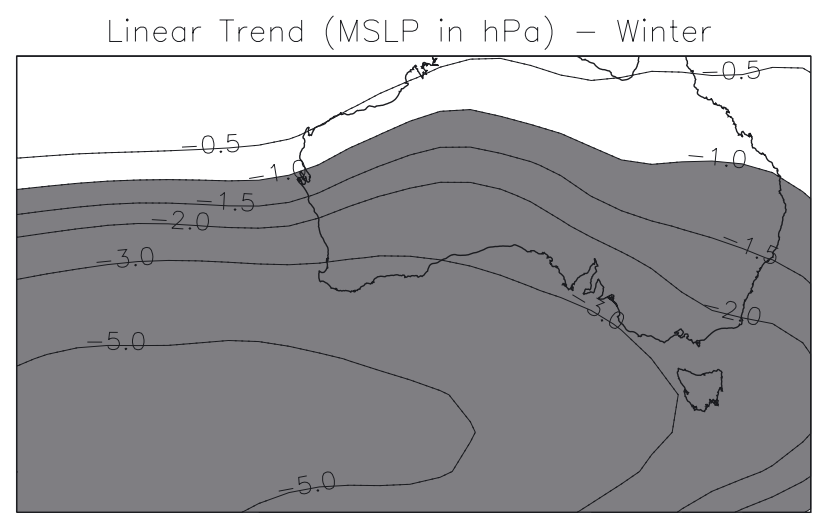

Linear Trend (PWTR in $\mathrm{mm}$ ) - Winter

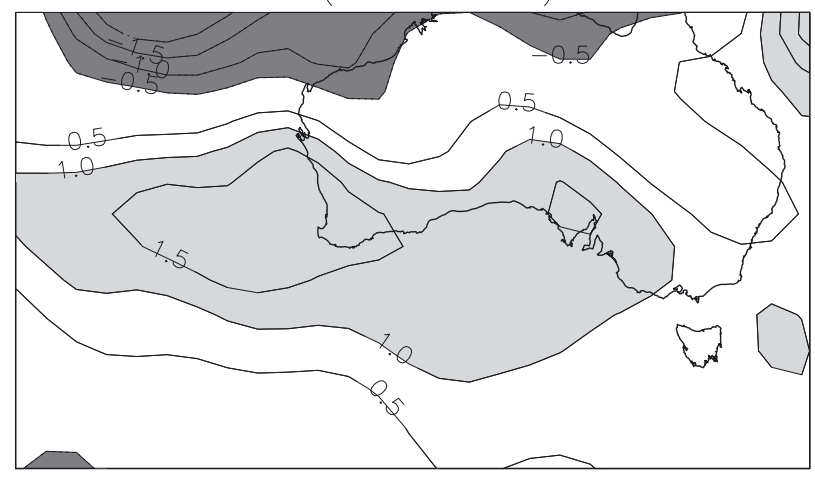

Fig. 8. Linear trend fitted for winter 1958-1998 and reproduced by the BMRC model simulating the climate of the 20th century for mean sea level pressure (MSLP) (top panel) and precipitable water (PWTR) (bottom panel)

Although not realistic, these trends are coherent with the large-scale forcing calculated by the C20C model simulation (Fig. 8). The model strengthens the storm track and extends it well north over the southern part of the Australian continent, and this is associated with a weakening of the high pressure belt. Trends for PWTR do not match the observed trends either; a large area of positive anomalies covering SWA. The downscaling SM responses to the increasing penetration of frontal systems over SWA and the increasing atmospheric moisture is to exhibit a positive rainfall trend, in particular at the tip of the continent.

Therefore, current climate models suffer from 2 limitations in reproducing the observed rainfall trend in this part of the world. The same BMRC model is unable to reproduce the large-scale atmospheric trends when forced by observed SSTs. This does not rule out SST anomalies as a cause of the observed local rainfall decline, since this model needs to be confirmed by other modelling studies to be proven robust. However, the second limitation, apparent in NNR direct rainfall, is that, even with a 'perfect' knowledge of the large-scale conditions, currently a model cannot reproduce this regional climate change. This limitation is likely to be a feature in most climate models using similar resolutions.

\section{DOWNSCALING OF COUPLED MODEL CLIMATE SIMULATIONS}

\subsection{Current climate}

The SM is applied to GCM control simulations to verify that the downscaling technique adds values to local model projections. Comparison with direct model outputs is only done with the BMRC and CSIRO models. Common problems in modelled rainfall are the lack of intense rainfall events, too widespread rainfall events in time and space, and the lack of small-scale features (McAvaney et al. 2001).

In this region, rain occurrence is overestimated by the CSIRO models and underestimated by the BMRC model. For all statistics (Table 3), the downscaling technique gives estimates within $10 \%$ of the observations; improvements are large in the case of large model bias (e.g. the BMRC model in spring). The models underestimate total rainfall in SWA: about $50 \%$ by the CSIRO model and between $20 \%$ in winter and $70 \%$ in spring by the BMRC model. At station level, the underestimation can be larger where orographically forced local maxima are not captured. The downscaling of the 2 GCMs gives area mean rainfall estimates within $10 \%$ of the observation, with a dry bias in spring, due to the underestimation of rain occurrences, as noted earlier.

Table 3. Reproduction of observed fraction of rain days and total rain amount (relative to observations) by climate model direct outputs (DMO) and using the analogue downscaling technique

\begin{tabular}{|lrrrr|}
\hline & \multicolumn{2}{c}{ BMRC } & \multicolumn{2}{c|}{ CSIRO } \\
& DMO & Analogue & DMO & Analogue \\
& & & & \\
Rain days (\%) & & & 112.3 & 96.5 \\
Winter & 106.4 & 104.1 & 119.2 & 88.5 \\
Spring & 60.1 & 92.7 & & \\
Total rainfall (mm) & & & 48.1 & 93.7 \\
Winter & 82.3 & 107.1 & 57.1 & 85.3 \\
Spring & 28.5 & 90.2 & & \\
& & & & \\
\hline
\end{tabular}

Table 4. Reproduction of the geographical rainfall ratio (relative to observations) by climate model direct outputs and using the analogue downscaling technique. Observations are given in the right column. Calculation of the gradient is explained in the text

\begin{tabular}{|crcccc|}
\hline & \multicolumn{2}{c}{ BMRC } & \multicolumn{2}{c|}{ CSIRO } & Obser- \\
& DMO Analogue & \multicolumn{2}{c}{ DMO Analogue } & vations \\
\hline Winter & 4.3 & 3.6 & 1.2 & 4.0 & 3.3 \\
Spring & 11.8 & 5.2 & 2.0 & 4.6 & 6.0 \\
\hline
\end{tabular}


The sharp variation in rainfall amount at the tip of the Australian continent is difficult to capture with climate models having limited resolution and only 6 grid points to cover the region. This gradient is quantified using the ratio between 3 stations in the far SW corner (Katanning, Dwellingup and Manjimup) and 3 stations further inland in the NE (Mount Magnet, Menzies and Wongan). This gradient is twice as large in spring as in winter (Table 4). Both models fail to reproduce this ratio. The BMRC model, which does not simulate any penetration of moisture over the continent, overestimates this ratio, while the CSIRO model underestimates it. The downscaling approach gives a reasonable estimate of this gradient, but without the strong seasonal cycle, in particular when applied to the CSIRO model.

In addition to the main seasonal statistics, the temporal pattern of rainfall is another important aspect of the local hydrology. In particular, extended periods of wet days generate important surface runoff, critical for the filling of dams and management of water resources. Probabilities of wet spell duration (Bates et al. 1998) are plotted for a selection of stations along a south to north axis: Manjimup, Corrigin and Mount Magnet (Fig. 9). The downscaled probabilities for both downscaled models are in better agreement than Direct Model Outputs (DMO) in all cases, and indeed provide an unbiased estimate for events up to the 99th percentile.

\subsection{Future rainfall trends}

First, future modelled trends for atmospheric predictors are analysed and compared with past trends. In winter, scenarios vary amongst the models (Fig. 10), all suggesting an increase in surface pressure over SWA, but disagreeing on the location and the intensity of the anomalies. The greatest anomalies are located SW of the tip of the continent in the BMRC model, south of the continent in the CSIRO model and west in the LMD model. Both the CSIRO and LMD models simulate anomalies of similar intensity: around $0.5 \mathrm{hPa}$ near the SWA region, while the BMRC model has a larger signal closer to the SW corner. The increase of MSLP over the continent is expected to reduce the penetration of frontal systems and further reduce the rainfall. These future changes are consistent with past MSLP trends, although the anomalies are pushed further south. The actual location and intensity of the anomalies should impact on the individual stations' rainfall trends. In spring (Fig. 11), the anomalies are more similar. The BMRC and LMD models agree well, while the CSIRO model exhibits a similar pattern but with a larger amplitude. The overall increase of MSLP over the southern ocean in the vicinity of SWA, which differs from the past observed trend, is likely to induce a shift in spring rainfall in the future.

Future projections for PWTR were also analysed, but are not shown for brevity. Projections are consistent amongst the 3 models, with zonal anomalies and a
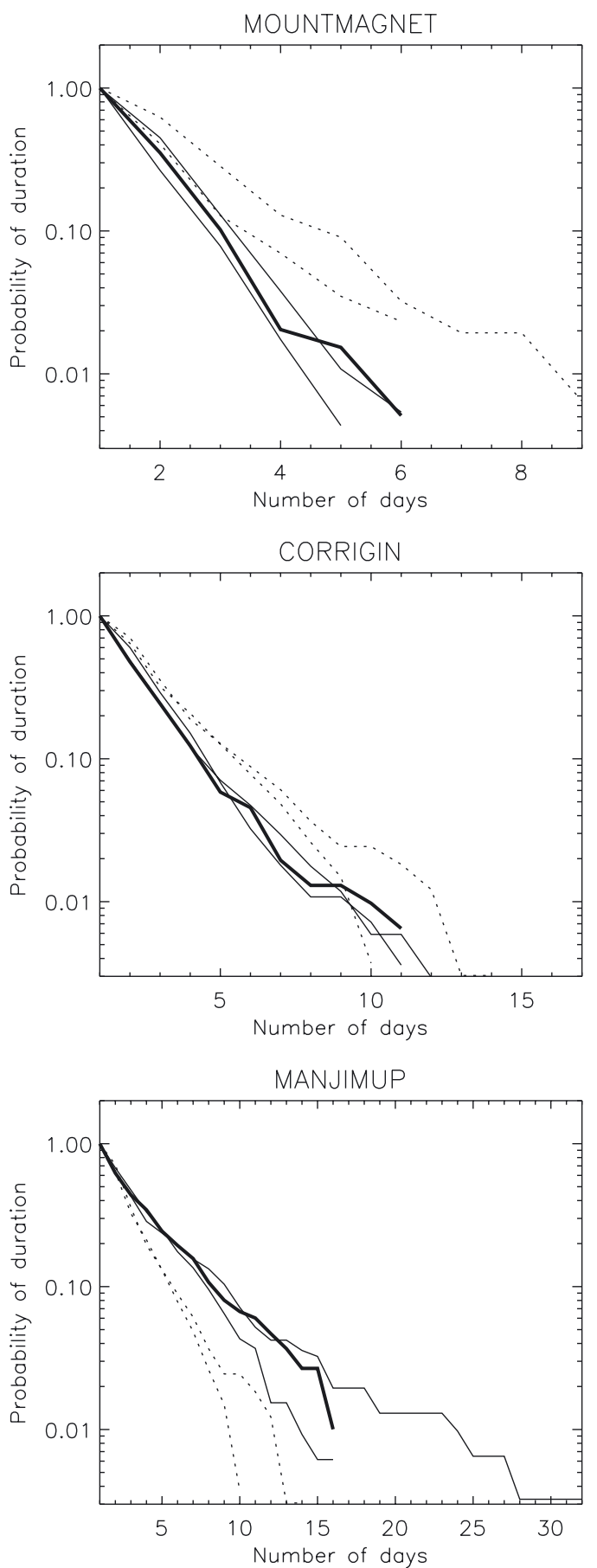

Fig. 9. Probabilities of wet spell duration in winter for 3 locations. Bold lines: observed values; thin lines: downscaling of 2 GCMs; dashed lines: GCM direct rainfall 

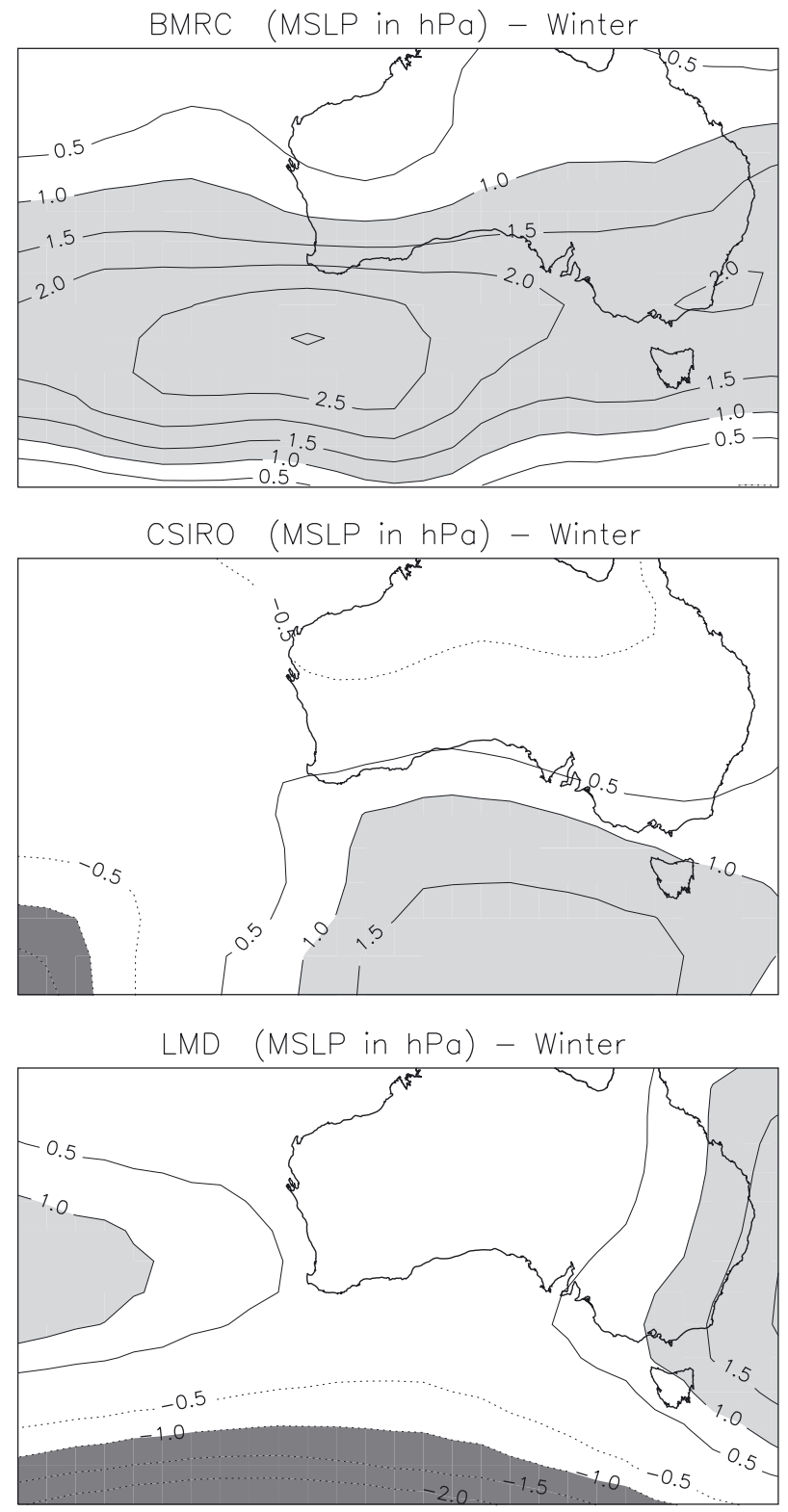

Fig. 10. Mean sea level pressure (MSLP) anomalies between transient and control climate in winter, simulated by the BMRC (top panel), CSIRO (middle panel) and LMD (bottom panel) models

maximum near the tropics, which decreases to values between 1.5 and $2 \mathrm{~mm}$ in the vicinity of SWA, in both winter and spring. PWTR anomalies are temperaturedriven, but the importance of this predictor in reproducing observed rainfall trends was demonstrated earlier. Therefore, the positive trend of this predictor should also impact future rainfall projections.

In agreement with large-scale predictors, in the dynamical models, the direct projections for rainfall show a drying trend for both winter and spring (Table 5). The range between the BMRC and CSIRO
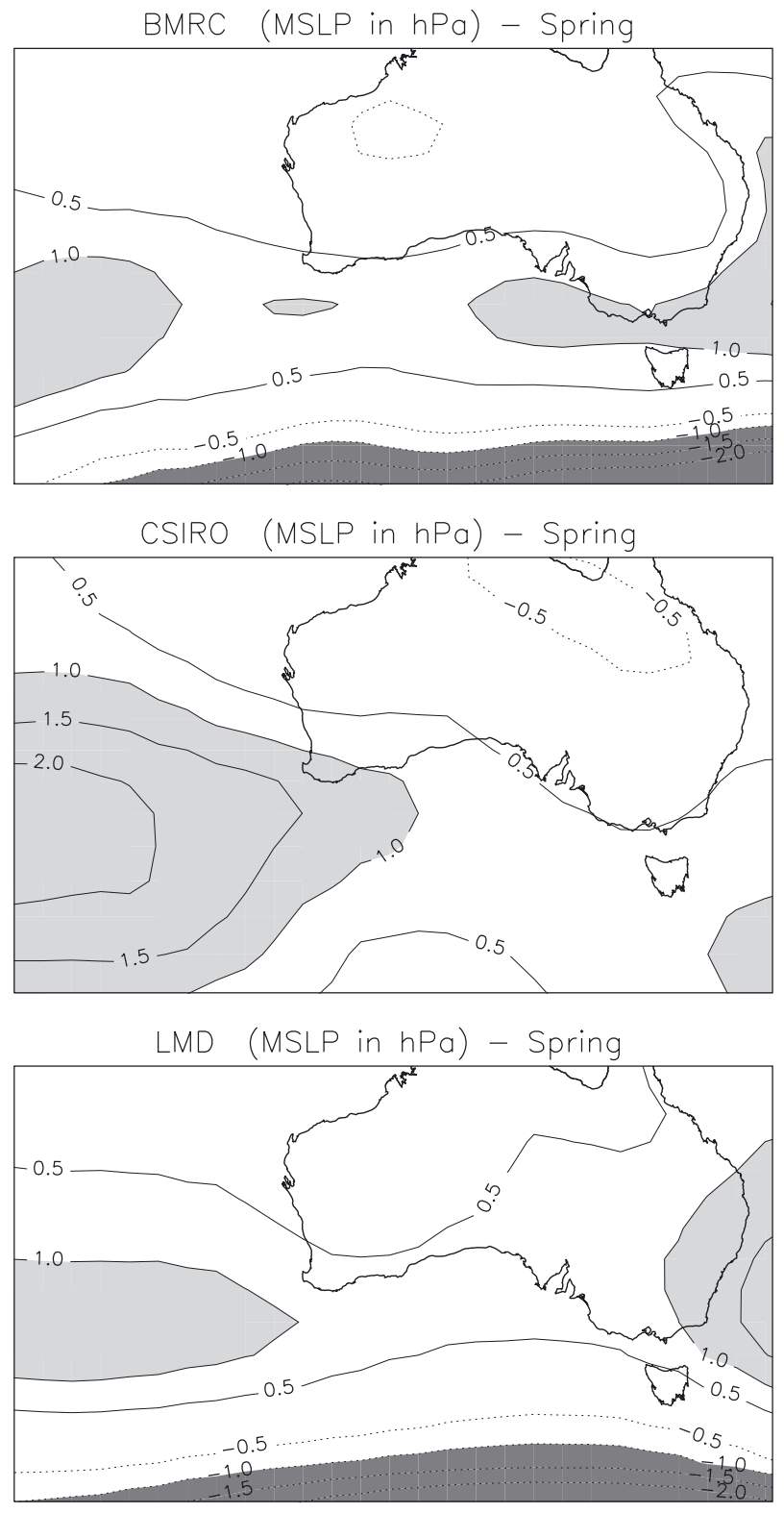

Fig. 11. Mean sea level pressure (MSLP) anomalies between transient and control climate in spring, simulated by the BMRC (top panel), CSIRO (middle panel) and LMD (bottom panel) models

models is large. The BMRC model suggests a strong reduction in winter, while the largest signal simulated by the CSIRO model is in spring. Downscaled future rainfall projections, averaged over the entire region, vary by a factor of 3, although the spread amongst projections is reduced, compared to DMO. All models point toward a reduction of total rainfall of 7 to $21 \%$ in winter. This is a further reduction of similar magnitude as the one experienced in the last 50 years. Rainfall occurrences are also reduced by a similar proportion, between 11 and $21 \%$ (Table 6). Spring projections of a 
Table 5. Reduction of total rainfall amount (\% of the current model climatologies) for climate model direct outputs (DMO) and analogue downscaled predictions (at 2 and 4 the current $\mathrm{CO}_{2}$ level)

\begin{tabular}{|lccrrrr|}
\hline & \multicolumn{3}{c}{ BMRC } & \multicolumn{2}{c}{ CSIRO } & \multicolumn{2}{c|}{ LMD } \\
& \multicolumn{2}{c}{ DMO Analogue } & DMO Analogue & $2 \times \mathrm{CO}_{2}$ & $4 \times \mathrm{CO}_{2}$ \\
\hline Winter & 32 & 21 & 4 & 7 & 11 & 16 \\
Spring & 12 & 13 & 25 & 22 & 17 & 32 \\
\hline
\end{tabular}

Table 6. Reduction in number of rain days (\% of the current model climatologies) for climate model direct outputs (DMO) and analogue downscaled predictions (at 2 and 4 the current $\mathrm{CO}_{2}$ level)

\begin{tabular}{|crcrrrr|}
\hline & \multicolumn{3}{c}{ BMRC } & \multicolumn{2}{c}{ CSIRO } & \multicolumn{2}{c|}{ LMD } \\
& \multicolumn{2}{c}{ DMO Analogue } & \multicolumn{2}{c|}{ DMO Analogue } & $2 \times \mathrm{CO}_{2}$ & $4 \times \mathrm{CO}_{2}$ \\
\hline Winter & 19 & 13 & 13 & 6 & 4 & 3 \\
Spring & 6 & 10 & 22 & 17 & 12 & 26 \\
& & & & & & \\
\hline
\end{tabular}

drying trend between 13 and $22 \%$ are more consistent across models, and are the opposite to what was observed during the last 40 years. This is consistent with future trends for predictors, in particular MSLP. Downscaled projections are ranked in the same order as direct model projections in both seasons, but the spread amongst the projections is reduced once the SM is applied. Rainfall occurrences are also reduced. However, in winter the reduction in rainfall occurrence is smaller than for rainfall amount (between 4 and $13 \%)$. This suggests that rainfall future trends are driven by rain occurrences in spring, but in winter rainfall intensity is also reduced.

On a station by station basis, some noticeable geographic features are worth mentioning (Fig. 12). In several cases, all 3 downscaling projections are similar, in particular in the SW tip of the continent where the past drying trend was observed, suggesting a good agreement amongst models with regards to a continuation of a climatic trend. Further north and inland, both the CSIRO and LMD model are consistent with the observed trend, showing a further increase of rainfall (i.e. negative drying trend in Fig. 12). The BMRC model differs, and simulates an extension of the reduced rainfall area. This inter-model difference is consistent with the larger and more widespread MSLP anomalies in the BMRC model (Fig. 10). In spring, the geographical patterns of the projected trends are more consistent amongst models than in winter, as expected from the strong consistency amongst predictor anomalies (Fig. 11). The CSIRO model has a larger signal for the predictors and the predictands. Predicted rainfall reductions in spring, compared to winter, are more widespread and exhibit less north-south contrast. Despite being in marked contrast with past rainfall observations, some confidence should be placed in the results, as they are highly consistent amongst models and in agreement with large-scale anomalies.

The impact of both predictors in winter has been further assessed by calculating rainfall future projections, based on MSLP and PWTR alone (Fig. 13). Both individual predictors produced weaker rainfall trends, confirming the earlier finding that both predictors have an impact on rainfall trends. Based on MSLP alone, trends in both the CSIRO and LMD models are very small. This is particularly noticeable in the SW corner, where all 3 models suggest a strong drying trend. The BMRC model simulates a similar trend with or without PWTR. In contrast, when only PWTR is considered, the BMRC model projects very small trends, as does the LMD model, while in the CSIRO model, the overall trend is similar than with the 2 predictors, although the north-south gradient is reduced. These
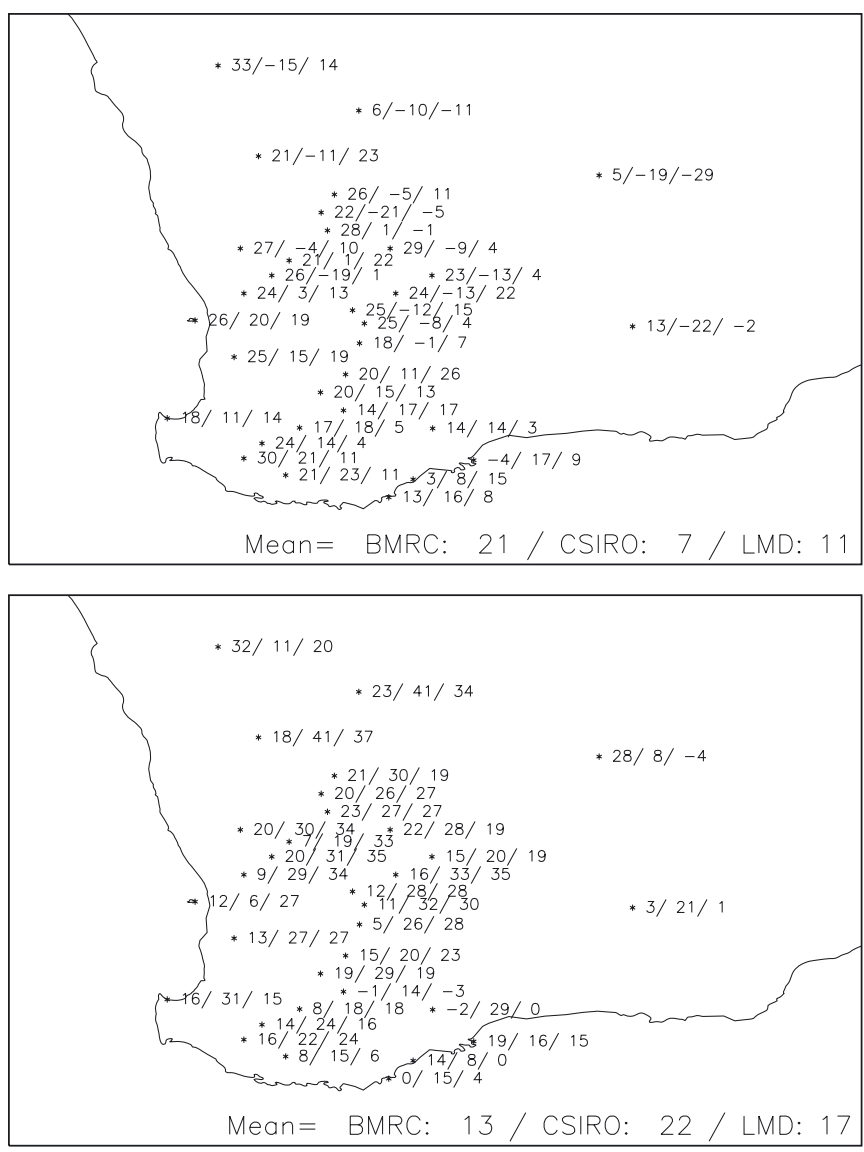

Fig. 12. Future drying trend predicted by the 3 climate models (BMRC/CSIRO/LMD) in winter (top panel) and spring (bottom panel), calculated as the reduction of rainfall (\% of the model control climate) 

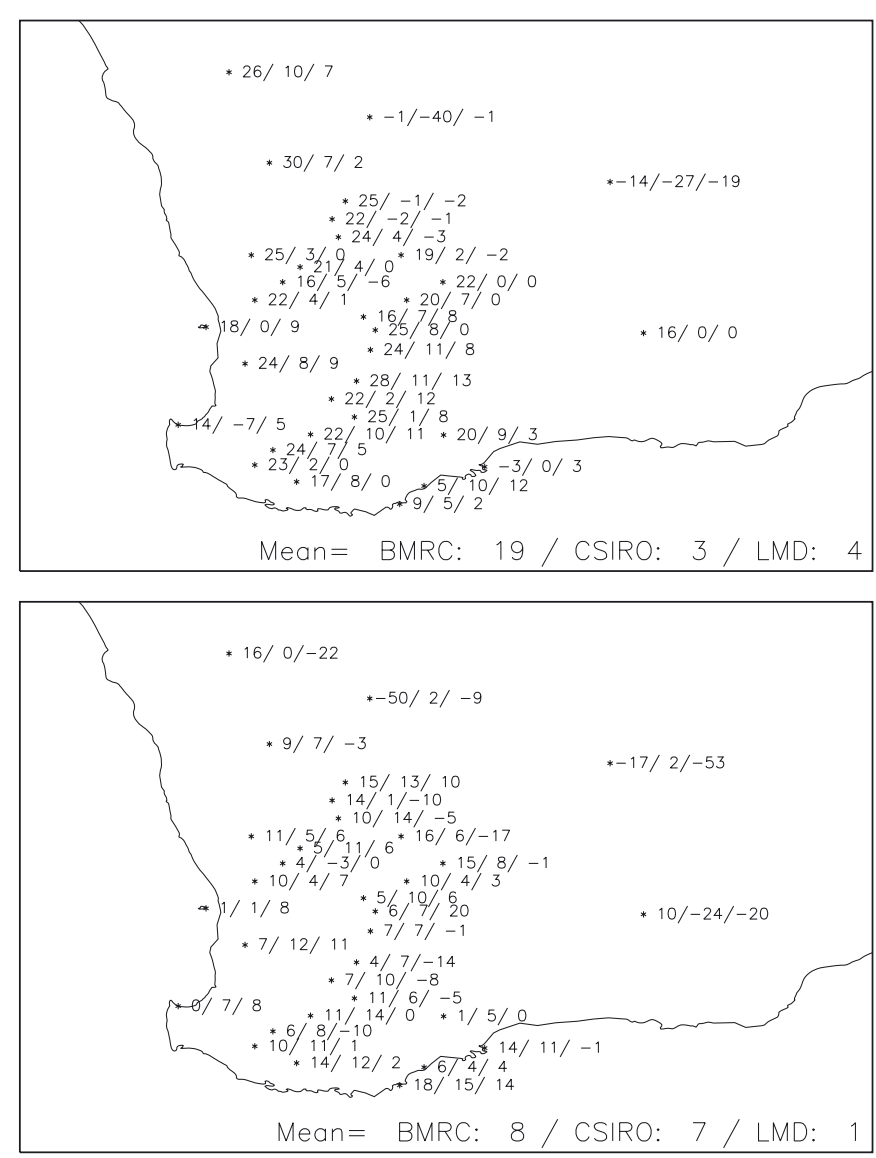

Fig. 13. Future drying trend predicted by the statistical model (SM) based on mean sea level pressure (MSLP) alone (top panel) and precipitable water (PWTR) alone (bottom panel), calculated as the reduction of rainfall ( $\%$ of the model control climate)

results suggest that both predictors are important to describe the future rainfall drying trend, but the importance and complementarity differs between models. The LMD model was further integrated until the $\mathrm{CO}_{2}$ equivalent level reached 4 times the current value. The downscaling technique was applied to 20 years of this simulation. Compared to the $2 \times \mathrm{CO}_{2}$ scenario, results show a intensification of the drying trend in both seasons. In spring the total rainfall is reduced by up to $32 \%$ (Table 5). The severity of the projections in the case of continuing anthropogenic greenhouse gas releases should be put in perspective with results obtained after stabilisation at the $2 \times \mathrm{CO}_{2}$ level. Longterm climate integrations have shown that after an initial shift toward a drier climate state the system recovers to current climate conditions (Cai et al. 2003).

\subsection{Change in rainfall extremes}

In addition to rain occurrences, water management depends on extreme rainfall: high daily values, long wet spells and high seasonal total are all critical to generate runoff. It was noted earlier that intense rainfall during the winter months was expected to be reduced. This result suggests that future trends are coherent with past trends as reported by Hennessy et al. (1999) and different from Yu \& Neil (1993). Indeed, the reduction of rainfall from days with more than $20 \mathrm{~mm}$ of rain are projected to be higher than the mean signal. This reduction ranged from $10 \%$ in the CSIRO model to $35 \%$ in the BMRC model, with $15 \%$ in the LMD model. Another important control of stream flow is the probability of wet spell duration. Wet spell duration, from the downscaling of the 3 global models' control and transient simulations are shown at 4 different sites in the far SW of the continent, where future trends were most significant (Fig. 14). All probabilities are normalised by the rainfall occurrences (i.e the probability of a wet spell to last one day is 1), and therefore are not impacted by the general reduction of rain occurrences projected by the models. In all cases, despite a range of uncertainties amongst models, a consistent tendency toward a reduction of probabilities of long wet spells is observed. In some cases this reduction can be quite large: for example, in Dwellingup the average length of a wet spell, which occurred $10 \%$ of the time (i.e. less than once a year), is reduced from 10 to $7 \mathrm{~d}$.

Another important aspect is the total rainfall amount per year recorded over the wet season from May to October (winter and spring). The interannual variability is rather large and total rainfall varies by a factor

Table 7. Highest, mean and lowest total rainfall (in $\mathrm{mm}$ ) over winter and spring, for each 20 yr period, averaged over the 32 sites. Good years: rainfall $>300 \mathrm{~mm}$; bad years: rainfall $<200 \mathrm{~mm}$

\begin{tabular}{|c|c|c|c|c|c|c|}
\hline & $\begin{array}{r}\text { Rai } \\
\text { Highest }\end{array}$ & $\begin{array}{l}\text { nfall }(\mathrm{m} \\
\text { Mean }\end{array}$ & $\begin{array}{l}\text { Lm) } \\
\text { Lowest }\end{array}$ & $\begin{array}{c}\text { No. of } \\
\text { good years }\end{array}$ & $\begin{array}{c}\text { No. of } \\
\text { bad years }\end{array}$ & $\begin{array}{l}\text { Interannual } \\
\text { range }\end{array}$ \\
\hline \multicolumn{7}{|l|}{ Observed } \\
\hline $1958-1977$ & 423 & 324 & 193 & 14 & 1 & 230 \\
\hline 1979-1998 & 399 & 297 & 197 & 8 & 1 & 202 \\
\hline \multicolumn{7}{|l|}{ Control } \\
\hline BMRC & 393 & 306 & 220 & 8 & 0 & 173 \\
\hline CSIRO & 359 & 285 & 210 & 7 & 0 & 149 \\
\hline LMD & 339 & 259 & 198 & 5 & 1 & 141 \\
\hline \multicolumn{7}{|l|}{$2 \times \mathrm{CO}_{2}$} \\
\hline BMRC & 384 & 249 & 180 & 2 & 3 & 204 \\
\hline CSIRO & 348 & 237 & 137 & 2 & 5 & 211 \\
\hline LMD & 296 & 221 & 164 & 0 & 5 & 132 \\
\hline $\begin{array}{l}\mathbf{4} \times \mathrm{CO}_{2} \\
\mathrm{LMD}\end{array}$ & 307 & 197 & 114 & 1 & 12 & 193 \\
\hline
\end{tabular}



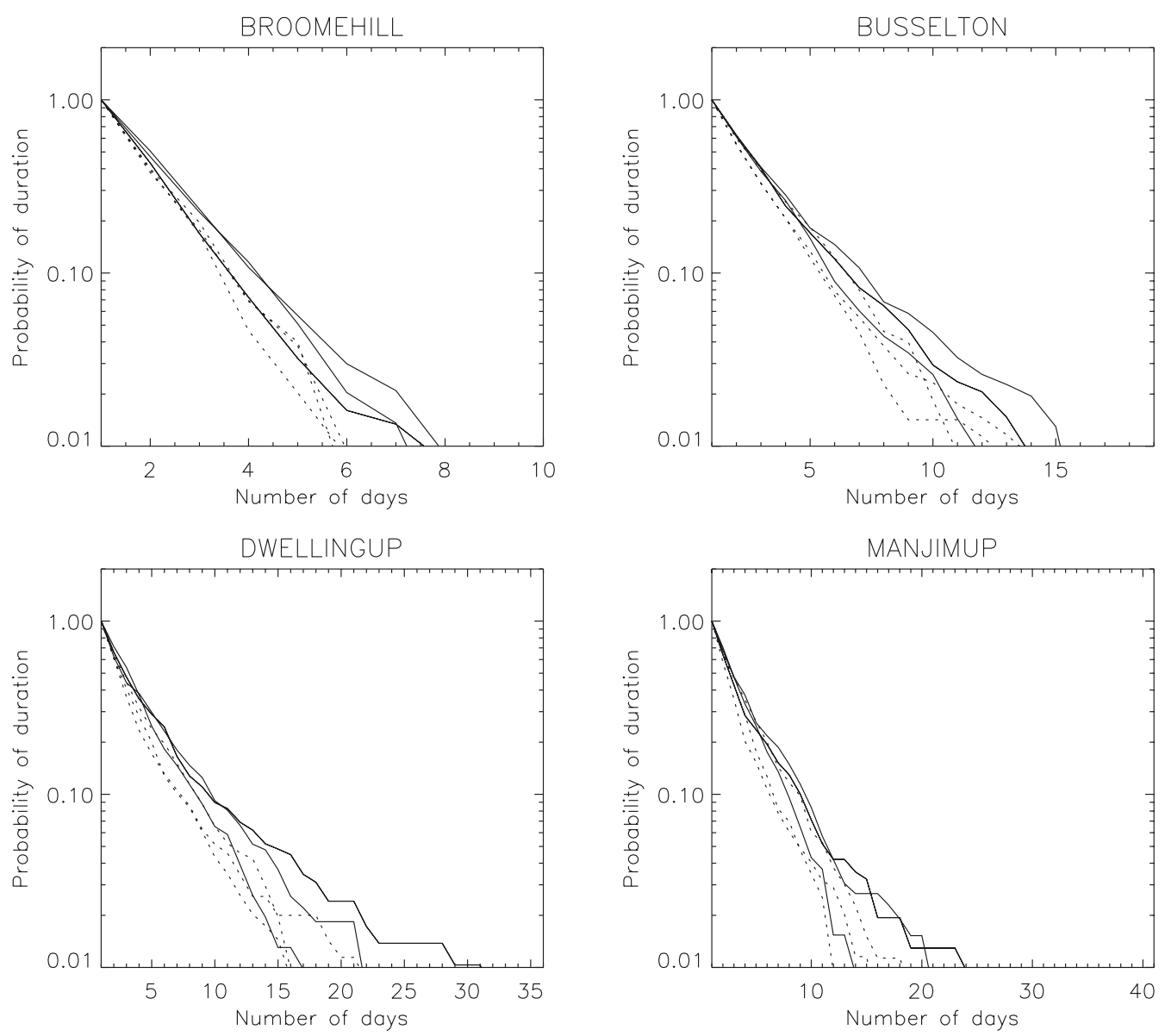

Fig. 14. Probabilities of wet spell duration in winter at 4 locations in the far SW corner of Western Australia. Thin lines: current climate; dashed lines: transient climate

of 2 (Table 7). One significant result of the observed trend is the reduction of 'good' rainfall years, which allow reservoirs to be replenished. Years were defined as good when the wet season average over the 32 locations was $>300 \mathrm{~mm}$. In contrast, during 'bad' years rainfall is $<200 \mathrm{~mm}$. Prior to the reduction in rainfall, good years were the norm with 14 such years out of 20 in the 1958-1977 period. This was reduced to 9 in the following 2 decades. The downscaling of the $20 \mathrm{yr}$ of each model control climate indicate similar, but lower numbers: 8 to 5, due mainly to a dry bias in the CSIRO model (and even more so in the LMD model) and a smaller than observed interannual variability (summarised by the difference between highest and lowest value) in all models. The number of high rainfall years is drastically reduced in all scenarios: 2 or fewer occurrences per 20 yr. Results on the most extreme year are less clear, amid a general reduction of the highest rainfall, there is a large spread amongst the projections. For example, with the $4 \times \mathrm{CO}_{2}$ simulations of the LMD model, despite a very large reduction of the mean total amount, the highest value is still rather high, and higher than in the $2 \times \mathrm{CO}_{2}$ projection. Indeed, despite the reduction of the mean rainfall, the interannual range, from control climate to future scenarios, increases in all cases. Another consequence is the increase of extreme years at the other end of the distribution. Bad years, which were rarely observed in the past $40 \mathrm{yr}$ and only reproduced in the simulation of the current climate by the LMD model, become more frequent (3 to 5 occurrences) with a doubling of the $\mathrm{CO}_{2}$ concentration, and become the norm with a $4 \times \mathrm{CO}_{2}$ scenario (12 out of $20 \mathrm{yr}$ ). Record low rainfall years are also projected to reach lower values.

\section{DISCUSSION AND CONCLUSIONS}

Analogue downscaling was shown to complement and improve direct coupled climate model results for SW Australia. It overcomes several shortcomings of direct model outputs, such as biased estimate of the mean, frequency, intensity and spatial pattern of rainfall. In all aspects investigated, rainfall obtained using 
the downscaling technique applied to the NCEP/ NCAR reanalyses is closer to the observations and improves the rainfall modelled by the NNR. The benefit of using a statistical downscaling approach to provide details of future rainfall trends at a regional scale was demonstrated.

SW Australia is of particular interest in this regard, as its climate has been nonstationary during the past 40 years; a drying trend was observed during the 1960s and 1970 s. The ability of the downscaling technique to reproduce this observed trend was crossvalidated. The key atmospheric predictors that explain the local behaviour are the MSLP and the amount of total moisture available in the atmospheric column, defined as precipitable water. The success of the technique suggests that a large part of the observed drying trend was driven by large-scale atmospheric forcings. However, the inability of the technique to reproduce precisely local trends prevents us from ruling out local factors such as land clearing, as possible contributors to local trends. Nevertheless, the downscaling model is able to reproduce a non-stationary climate, which adds confidence in the ability of the technique to provide unbiased future rainfall estimates.

Future rainfall trends were obtained by applying the statistical model to transient simulations of projected future climate change according to the IS92a emission scenario. Results suggest a future drying trend in winter over the next 50 years, similar in magnitude to the past trend. Projections are consistent across all 3 climate models, with fewer differences than amongst direct model projections. This consistency adds confidence and reduces local uncertainties. Future trends also suggest reduced rainfall in spring, as opposed to the past decades, and a reduction of extreme rainfall events, i.e. heavy rainfall days and long wet spells. Furthermore, years with large total rainfall over the wet season are likely to become fewer, while very low rainfall years are projected to increase by a factor of 5 .

Overall, the results obtained with the downscaling technique are similar to those of direct model projections; nevertheless, uncertainties amongst models are reduced and more detailed features emerged from this approach. The similarity between the atmospheric trend analyses in the past decades and the one predicted by the GCMs suggests a continuing climatic evolution. However, the study pointed out several aspects that are likely to aggravate the situation in the future: the reduction of rainfall across the entire wet season and the reduction in extreme events are both likely to have great consequences for water management and other human activities impacted by rainfall. The possibility of tracing back future rainfall projections to modelled large-scale climate changes for which models are considered more reliable adds to our confidence in the results.
Acknowledgements. The author is grateful to L. Chambers, W. Drosdowsky, S. Charles and N. Nicholls for providing helpful comments on the original manuscript. Modelled data were kindly provided by R. Colman from the Bureau of Meteorology Research Centre (BMRC), P. Whetton from Commonwealth Scientific and Industrial Research Organization (CSIRO), and L. Fairhead from the Laboratoire de Météorologie Dynamique (LMD). The author is supported by a grant from the Australian Greenhouse Office.

\section{LITERATURE CITED}

Allan RJ, Haylock MR (1993) Circulation features associated with the winter rainfall decrease in southwestern Australia. J Climate 6:1356-1367

Barnett TP, Preisendorfer RW (1978) Multifield analog prediction of short-term cimate fluctuations using a climate state vector. J Atmos Sci 35:1771-1787

Bates BC, Charles SP, Hughes JP (1998) Stochastic downscaling of numerical climate model simulations. Env Model Software 13:325-331

Braconnot P, Marti O, Joussaume S (1997) Adjustment and feedbacks in a global coupled ocean-atmosphere model. Clim Dyn 13:507-519

Cai WJ, Whetton PH, Karoly DJ (2003) The response of the Antarctic Oscillation to increasing and stabilised atmospheric $\mathrm{CO}_{2}$. J Clim 16:1525-1538

Charles SP, Bates BC, Whetton PH, Hughes JP (1999) Validation of downscaling models for changed climate conditions: case study of southwestern Australia. Clim Res 12:1-14

Cubash U, Meehl GA, Boer GJ, Stouffer R and 5 others (2001) Projections of future climate change. In: Climate change 2001, the scientific basis, Chap. 9. Contribution of Working Group I to the 3rd Assessment Report of the IPCC, Cambridge University Press, Cambridge

Frederiksen CS, Zheng X (2004) Variability of seasonal-mean fields arising from intraseasonal variability. Part II: Application to NH winter circulations. Clim Dyn (in press)

Gentilli J (1972) Australian climate patterns. Nelson, Melbourne

Gordon HB, O'Farrel SB (1997) Transient climate change in the CSIRO coupled model with dynamic sea-ice. Mon Weather Rev 125:975-1007

Hennessy KJ, Suppiah R, Page CM (1999) Australian rainfall changes, 1910-1995. Aust Meteor Mag 48:1-13

Houghton JT, Ding Y, Griggs DJ, Noguer M, van der Linden PJ, Dai X, Maskell K, Johnson CA (2001) Climate change 2001, the scientific basis. Contribution of Working Group I to the Third Assessment Report of the Intergovernmental Panel on Climate Change. IPCC, Cambridge University Press, Cambridge

Hubert P (1997) Change points in meteorological time series. In: Subba Rao T, Priestley MB, Lessi O, (eds) Applications of times series analysis in astronomy and meteorology. Chapman \& Hall, London, p 319-412

IOCI (1999) Towards understanding climate variability in south western Australia. Research reports on the First Phase of the Indian Ocean Climate Initiative. IOCI Tech Rep, Perth

IOCI (2001) Second research report: towards understanding climate variability in south western Australia. Research reports on the Second Research Phase of the Indian Ocean Climate Initiative. IOCI Tech Rep, Perth

Kalnay E, Kanamitsu M, Kistler R, Collins W, and 19 others (1996) The NCEP/NCAR 40-year reanalysis project. Bull Am Meteorol Soc 77:437-471 
Kattenberg A, Giorgi F, Grassl H, Meehl GA and 5 others (1996) Climate change 1995, the science of climate change. Chapter 6: climate models - projections of future climate. Contribution of Working Group I to the Second Assessment Report of the Intergovernmental Panel on Climate Change. IPCC, Cambridge University Press, Cambridge

Katz RW (2002) Techniques for estimating uncertainty in climate change scenarios and impact studies. Clim Res 20(2): 167-185

Kistler R, Kalnay E, Collins W, Saha S, and 9 others (2001) The NCEP/NCAR 50-year reanalysis: monthly means CDROM and documentation. Bull Am Meteorol Soc 82: $247-267$

Lambert SJ, Boer GJ (2001) CMIP1 evaluation and intercomparison of coupled climate models. Clim Dyn 17:83-106

Lavery B, Kariko A, Nicholls N (1992) A historical rainfall data set for Australia. Aust Meteor Mag 40:33-39

Lorenz EN (1969) Atmospheric predictability as revealed by naturally occurring analogues. J Atmos Sci 26:636-646

Martin E, Timbal B, Brun E (1997) Downscaling of general circulation model outputs: simulation of the snow climatology of the French Alps and sensitivity to climate change. Clim Dyn 13:45-56

McAvaney BJ, Colman RA (1993) The BMRC AGCM: AMIP configuration. Tech Rep 38, Bureau of Meteorology Research Centre, Melbourne

McAvaney BJ, Covey C, Joussaume S, Kattsov V, and 6 others (2001) Climate change 2001, the scientific basis, Chap. 8: model evaluation. Contribution of Working Group I to the 3rd Assessment Report of the IPCC. IPCC, Cambridge University Press, Cambridge

McCarthy JJ, Canziani OF, Leary NA, Dokken DJ, White KS (2001) Climate change 2001: impacts, adaptation and vulnerability. Contribution of Working Group II to the 3rd Assessment Report of the IPCC. IPCC, Cambridge University Press, Cambridge

Meehl GA, Boer GJ, Covey C, Latif M, Stouffer RJ (2000) The Coupled Model Intercomparison Project (CMIP). Bull Am Meteorol Soc 81:313-318

Nicholls N, Chambers L, Haylock M, Frederiksen C, Jones D, Drosdowsky W (1999) Towards understanding climate variability in south western Australia. In: Research reports on the First Phase of the Indian Ocean Climate Initiative. CSIRO Tech Rep, Perth, p 1-54

Palutikof JP, Winkler JA, Goodess CM, Andresen JA (1997) The simulation of daily temperature time series from GCM output. Part I: comparison of model data with observations. J Clim 10:2497-2513

Editorial responsibility: Otto Kinne, Oldendorf/Luhe, Germany
Power SB, Colman RA, McAvaney BJ, Dahni RR, Moore AM, Smith NR (1993) The BMRC coupled atmosphere/ocean/ sea-ice model. Res Rep 37, Bureau of Meteorology Research Centre, Melbourne

Raper SCB, Cubasch U (1996) Emulation of the results from a coupled general circulation model using a simple climate model. Geophys Res Lett 23:1107-1110

Risbey JS, Lamb PJ, Miller RL, Morgan MC, Roe GH (2002) Exploring the structure of regional climate scenarios by combining synoptic and dynamic guidance and GCM output. J Clim 15:1036-1050

Skelly WC, Henderson-Sellers A (1996) Grid box or grid point: what type type of data do GCMs deliver to climate impact researchers? Int J Climatol 16:1079-1086

Smith I, Hunt B, Watterson I, Elliott T (2001) Towards understanding climate variability in south western Australia. In: Research reports on the Second Phase of the Indian Ocean Climate Initiative. CSIRO Tech Rep, Perth, p 53-96

Timbal B, McAvaney BJ (2001) An analogue-based method to downscale surface air temperature: application for Australia. Clim Dyn 17:947-963

Timbal B, Dufour A, McAvaney BJ (2003) An estimate of future climate change for western France using a statistical downscaling technique. Clim Dyn 20:807-823

Van Den Dool HM (1994) Searching for analogues, how long must we wait? Tellus 46A:314-324

Wilby RL, Wigley TM, Conway D, Jones PD, Hewitson BC, Main J, Wilks DS (1998) Statistical Downscaling of General Circulation Model output: a comparison of methods. Water Resour Res 34:2995-3008

Wilks DS (1995) Statistical methods in the atmospheric sciences. Academic Press, London

Wright PB (1974a) Seasonal rainfall in southwestern Australia and the general circulation. Mon Weather Rev 102: 219-225

Wright PB (1974b) Temporal variations of seasonal rainfall in southwestern Australia. Mon Weather Rev 102:226-232

Yu B, Neil DT (1993) Long-term variations in regional rainfall in the southwest of western Australia and the difference between average and high density rainfalls. Int J Climatol 13:77-88

Zorita E, von Storch H (1999) The analog method as a simple statistical downscaling technique: comparison with more complicated methods. J Clim 12:2474-2489

Zorita E, Hughes JP, Lettemaier DP, von Storch H (1995) Stochastic characterization of regional circulation patterns for climate model diagnosis and estimation of local precipitation. J Clim 8:1023-1042

Submitted: October 14, 2003; Accepted: May 13, 2004

Proofs received from author(s): June 11, 2004 